\title{
Animal Models of Peripheral Neuropathies
}

\author{
Ahmet Höke \\ Published online: 14 March 2012 \\ (C) The American Society for Experimental NeuroTherapeutics, Inc. 2012
}

\begin{abstract}
Peripheral neuropathies are common neurological diseases, and various animal models have been developed to study disease pathogenesis and test potential therapeutic drugs. Three commonly studied disease models with huge public health impact are diabetic peripheral neuropathy, chemotherapy-induced peripheral neuropathy, and human immunodeficiency virus-associated sensory neuropathies. A common theme in these animal models is the comprehensive use of pathological, electrophysiological, and behavioral outcome measures that mimic the human disease. In recent years, the focus has shifted to the use of outcome measures that are also available in clinical use and can be done in a blinded and quantitative manner. One such evaluation tool is the evaluation of epidermal innervation with a simple skin biopsy. Future clinical trials will be needed to validate the translational usefulness of this outcome measure and validation against accepted outcome measures that rely on clinical symptoms or examination findings in patients.
\end{abstract}

Keywords Diabetic neuropathy - Diabetic autonomic neuropathy Chemotherapy · Toxic neuropathy · Human immunodeficiency virus $\cdot \mathrm{HIV}$-associated sensory neuropathy

\section{Introduction}

Peripheral neuropathies are diseases of the peripheral nerves in which either the axon or the myelin-forming cells (Schwann

\footnotetext{
A. Höke $(\bowtie)$

Departments of Neurology and Neuroscience, Johns Hopkins University School of Medicine, Johns Hopkins Hospital,

Baltimore, MD 21205, USA

e-mail: ahoke@jhmi.edu
}

cells) display dysfunction due to metabolic, toxic, infectious, or genetic causes. Peripheral neuropathies affect many people worldwide, and in fact they are one of the most common neurological disorders, affecting nearly 20 million people in the United States alone [1]. Patients often experience symptoms depending on the type of the nerve fiber affected: motor nerve fiber involvement leads to muscle weakness and wasting; involvement of autonomic nerve fibers leads to autonomic dysfunction, which may manifest as orthostatic hypotension, cardiac dysthymia, abnormalities of sweating, incontinence, erectile dysfunction, or gastrointestinal symptoms, such as persistent nausea, vomiting, constipation, or diarrhea; proprioceptive sensory fiber involvement leads to ataxia and poor balance; and finally involvement of the other sensory fibers may lead to numbness and paresthesias, sometimes painful [2]. Diagnosis of peripheral neuropathy is often made based on history (i.e., the patient's symptoms), examination findings that corroborate involvement of specific nerve fiber types, and ancillary testing, such as nerve conduction studies, electromyography, and blood tests. Apart from autoimmune neuropathies, there are no effective therapies that deal with the underlying pathogenic mechanism of axonal degeneration or Schwann cell dysfunction. Although many symptomatic therapies exist that deal with painful symptoms of peripheral neuropathies, these are not effective in a large group of patients, and there is a huge need to develop mechanism based effective therapies that stop and reverse axonal degeneration.

Development of effective mechanism-based therapies will need to rely on the use of appropriate animal models that replicate the essential features of the peripheral neuropathy and use appropriate outcome measures that are relevant to the pathogenesis of the disease. Unfortunately, the literature is filled with failed clinical trials that relied on preclinical data using animal models that may not have been the most optimum models or outcome measures irrelevant to the underlying disease pathogenesis. A classical example of this issue is the use of small changes in nerve conduction velocity in diabetic animal models and multiple failed clinical 
trials with aldose reductase inhibitors [3]. This review will focus on 3 common diseases that cause peripheral neuropathy and outline the past, present, and future of animal models in the use of mechanistic studies and drug development.

\section{Diabetic Neuropathy}

Diabetic neuropathy represents a group of neuropathies that can be classified according to the distribution of deficits and the predominant involvement of motor, sensory, and autonomic nerve fibers [4-6]. The most frequent form, the diabetic polyneuropathy (DPN), is clinically characterized by paresthesias and pain, which are accompanied by modest to severe sensory deficits. Symptoms are distributed symmetrically in a length dependent stocking and glove fashion [5]. DPN is the most frequent complication of diabetes mellitus and occurs in 13 to $40 \%$ of all diabetic individuals, affecting both types 1 and 2 diabetic patients. Several excellent reviews dealing with pathogenesis of diabetic neuropathy have been published in the recent years [5, 7-11], but they will not repeated here.

Pathologically, diabetic polyneuropathy is characterized by multi-focal axon loss, which includes large and small diameter fibers [12-15]. Apart from axonal degeneration, demyelination and remyelination are common pathological features that can be found in sural nerve biopsies [14, 15]. These morphological changes go along with endoneurial microangiopathy, consisting of microthrombosis, perivascular basement membrane thickening, and degeneration of pericytes. Current concepts assume that the pathogenesis of diabetic polyneuropathy is multifactorial and involve microvascular injury, as well as metabolic causes.

Multiple animal models of DPN have been developed in the context of modeling both types 1 and 2 diabetes. An excellent recent review outlines the various mouse models of DPN with the typical behavioral and morphological features [16]. However, earlier rodent models of diabetes relied on rats, and the first models used streptozotocin, a toxin to pancreatic beta cells. Injection of a single dose of streptozotocin caused rapid induction of hyperglycemia, and it mimicks type 1 diabetes mellitus $[17,18]$. Soon after the initial development of the streptozotocin-induced diabetes mellitus model, investigators recognized that the pathological changes in the peripheral nerves of these rats mirrored what has been seen in patients with DPN; they exhibited axonal atrophy, axonal degeneration, and demyelination [19-21]. These findings, however, were not very consistent across different models, and only a careful study was able demonstrate that streptozotocin-induced diabetic rats had distal axonal degeneration similar to human DPN, in which the degeneration starts in the most distal nerves in a "dying-back" fashion [22]. In typical streptozotocininduced diabetic rats, the peroneal nerves may not show obvious signs of large myelinated axonal degeneration, but they often show axonal atrophy, which requires careful nerve morphometric studies that are tedious and time consuming. In addition, the distal most parts of the peroneal nerves, within the intramuscular branches, show signs of axonal degeneration [22] complicating quantitation in drug development studies that rely on evaluation of many nerves in a feasible manner.

Because of the time consuming nature of the nerve morphometry and inconsistencies regarding the site of axonal degeneration that is seen, many investigators have relied on a more consistent feature of streptozotocin-induced DPN model (i.e., slowed conduction velocity in both motor and sensory nerves [22, 23]. After these initial observations, changes in nerve conduction velocity were used as the sole outcome measure in the evaluation of therapeutic benefit of first aldose reductase inhibitor, CP45634 [24]. Because of that study, many preclinical studies on various aldose reductase inhibitors that eventually resulted in large phases 2 and 3 clinical trials relied on reversal of conduction velocity changes as 1 of the primary outcome measures. Although it is unclear if reliance on nerve conduction velocity in preclinical models is the cause of failure of many aldose reductase inhibitors in clinical trials [25], it did likely play a role.

In patients with DPN, it is unclear if changes in nerve conduction velocity actually have any symptomatic correlates. Most early DPN patients experience symptoms consistent with abnormalities in the unmyelinated C-fiber populations and the sensory paresthesias may not be related to changes in nerve conduction velocities of the large myelinated fibers. An important progress in clinical evaluation of peripheral neuropathies, including DPN, has been the development of skin biopsies to evaluate intraepidermal nerve fibers [26, 27]. Staining of simple punch biopsies of skin at various sites in the legs with a pan-axonal marker, pgp9.5 reveals exquisite detail of unmyelinated $\mathrm{C}$-fibers and the distal epidermal branches of small myelinated axons. Although it is a relatively less invasive method (compared to sural or superficial peroneal nerve biopsies), findings in skin biopsies correlate better with clinical features in DPN patients [28, 29], especially when compared to electrophysiological parameters. In recent years, quantitation of intraepidermal nerve fiber density has been applied to both streptozotocin-induced rat [30] and mouse $[31,32]$ models of DPN, and mouse models of peripheral neuropathy seen in type 2 diabetes [33, 34]. Use of intraepidermal nerve fiber density as a true morphological correlate of the degree of sensory axonal loss is likely to improve the usefulness of rodent models of DPN, both in mechanistic studies and in preclinical efficacy studies of potential therapeutic drugs. Recent examples of drugs demonstrating efficacy in reversing loss of epidermal innervation in diabetic rats and mice include drugs aimed at different molecular mechanisms of DPN [35-40]. It remains to be seen whether these drugs fare better in clinical trials compared to previous drugs that relied on changes in nerve conduction velocity as the 
primary outcome measures in preclinical studies. Nevertheless, going forward, it is reasonable to advocate reliance on intraepidermal nerve fiber density quantitation as the primary outcome measure in preclinical animal models of DPN, while we wait for the validation of intraepidermal nerve fiber density in clinical trials of DPN.

There are, however, a few caveats to the use of intraepidermal nerve fiber density quantitation in preclinical animal models. First, quantitation methods and site of skin biopsies differ among various researchers. Absolute numbers of intraepidermal nerve fiber densities cannot be compared across different research groups, so inclusion of appropriate control groups is an absolute necessity in any study involving rodent models of DPN. Another confounding issue is the variability in the normal density of intraepidermal nerve fibers in different genetic backgrounds of mice and rats. This issue has been recognized in behavioral testing, but it is also true for epidermal innervation. Comparison of different mouse or rat models of DPN has to take this variability into consideration. A consensus statement about the appropriate outcome measures to be used in animal models of DPN and standardization of quantitative measures is a necessity in the field.

Having focused on the use of electrophysiology and morphological evaluations in rodent models of DPN, it is important to point out that behavioral testing is also of significant value. Streptozotocin-induced rat models of DPN have been used to evaluate thermal hyperalgesia using the tail flick test $[41,42]$ and the hot plate method [41, 43]; mechanical hyperalgesia has been used to evaluate the Randall-Sellito method $[41,44,45]$; mechanical allodynia has been used to evaluate Von Frey filaments [46]; and chemical allodynia has been used to evaluate formalin injection to the paw $[41,43,46$, 47]. In addition to the streptozotocin model in the normal genetic background, there are 2 well-known commercially available lines that develop insulin-dependent type 1 diabetes (Bio-breeding Worcester - BB/W) [48] and type 2 diabetes (Zucker diabetic rats) [49]. Both rats have been shown to develop behaviors consistent with neuropathy. These rats display thermal hyperalgesia in the tail flick test [42], as well as the paw withdrawal method described by Hargreaves [50-53]. In addition, they develop mechanical allodynia as measured using Von Frey filaments [50].

Compared to rats, mouse models of diabetes offer a big advantage; different genetic backgrounds can be induced to have diabetes type 1 with streptozotocin, and the effect of gene knockouts or overexpression can be studied. Furthermore, mouse models of type 2 diabetes, in which hyperglycemia develops for a longer period of time and exhibits other features of patients with type 2 diabetes (e.g., obesity, hyperlipidemia, and so forth) may mimic the human condition better. Sullivan et al. [16] recently reviewed all of the available mouse models of DPN and detailed their metabolic, electrophysiological, and behavioral features. There were few of these mouse models (BKS-db/db and B6-db/db [54], and B6-ob/ob [33]) that stand out, as they feature typical findings of DPN in the context of obesity and diabetes. Both of these mouse models feature disruption of the leptin-signaling pathway leading to obesity. Future clinical trials for DPN in type 2 diabetes will likely require validation of potential therapies in multiple mouse models including these.

As interest in impaired glucose tolerance and peripheral neuropathy has increased, a pre-diabetic model of peripheral neuropathy has been developed [34]. In this model of prediabetes, mice are fed a high-fat diet and develop features that mimic alimentary obesity, including high insulin and free fatty acids levels, as well as hyperglycemia. The advantage of this model is that studies are carried out in a normal genetic background. Behavioral characteristics displayed by these mice include mechanical allodynia and thermal hyperalgesia. These mice, however, do not display any significant changes in nerve pathology; therefore, their use in pre-clinical efficacy studies awaits further validation.

The behavioral outcome measures previously mentioned have been useful in preclinical testing of potential symptomatic treatment of neuropathic pain in DPN. Examples include efficacy of alleviating neuropathic pain behavior in rat models of DPN using tricyclic antidepressants $[52,53$, 55, 56] and morphine [55]. Clinical trials demonstrating efficacy with tricyclic antidepressants [57-61] and opioids $[62,63]$ provide further validation of the usefulness of these outcome measures.

In addition to the typical DPN, both types of diabetes mellitus are major causes of autonomic neuropathy. Prevalence of autonomic nervous system involvement in types 1 and 2 diabetes is as high as 90\% [64-66]. Evaluations of autonomic function in animal models of diabetes have relied on the typical induced or genetic models of rat and mouse diabetes [67-71]. A common pathological feature of both human diabetic autonomic neuropathy and experimental diabetic autonomic neuropathy is the presence of neuroaxonal dystrophy in the autonomic ganglia $[72,73]$. With experimental therapeutics, development of these neuroaxonal pathologies can be prevented or reversed [74, 75], but it remains to be seen whether these successes in experimental models of diabetic autonomic neuropathy correspond to clinical successes.

\section{Chemotherapy-Induced Peripheral Neuropathy}

Peripheral neuropathy is one of the most common dose-limiting complications of chemotherapy. Incidence of chemotherapyinduced peripheral neuropathy (CIPN) can be as high as 80 to $90 \%$ of patients receiving chemotherapy, but as typical of most toxic neuropathies, a large proportion of patients improve once the offending drug is stopped. However, up to half of the patients with CIPN experience long-term neuropathic 
symptoms, including neuropathic pain, ataxia, and distal weakness. There are excellent reviews on CIPN and details of clinical presentations and potential mechanisms of actions of various chemotherapeutic drugs, but they will not be discussed here $[76,77]$. Instead, the focus in this article is on the animal models and the outcome measures used to evaluate them, and how faithfully these models mimic the human disease.

CIPN is most common in chemotherapeutic regimens that include taxanes (docetaxel or paclitaxel), platinum compounds (cisplatin, carboplatin, and oxaliplatin) and others such as vincristine, thalidomide, suramin, and bortezomib. In parallel, various investigators used similar drugs to model CIPN in mice and rats [78-86]. Often these models demonstrated many of the neuropathological changes seen in the human disease. Most of these models also exhibited typical electrophysiological abnormalities expected in CIPN, reduced nerve action potentials, and in some cases reduced conduction velocities. Careful behavioral examination of these animals revealed findings consistent with neuropathic pain. Unsettling in the field, however, are the significant differences in outcome measures used, and pathological, electrophysiological, and behavioral abnormalities observed in different laboratories. There are many causes of such discrepancies, and these include the genetic background of the animal used, mode of administration (intravenous vs intraperitoneal), dose and duration of drug administration, and extent and detail of outcome measures used in the evaluation of peripheral neuropathy. We can focus on paclitaxel-induced neuropathy as a case study to outline the issues in animal modeling CIPN.

Earlier models of paclitaxel-induced neuropathy used local injections of the drug subperineurially and demonstrated axonal swelling and demyelination at the injection site, and axonal degeneration distal to it $[78,87]$. However, it was clear that this approach was not appropriate to model the human disease. Others used repeated intraperitoneal injections to Wistar rats to mimic a course of chemotherapy [82]. In the high-dose treated animals $(16 \mathrm{mg} / \mathrm{kg}$ once a week for 5 weeks), there was mild axonal loss, mitochondrial swelling, and evidence of "Schwann cell activation" with minimal demyelination. Compared to the intraperitoneal administration, intravenous dosing (even just 2 doses at 12-18 mg/kg 3 days apart) in SpragueDawley rats resulted in severe large fiber sensory neuropathy with axonal degeneration and hypomyelination in the dorsal roots, which slowed conduction velocity in motor and sensory nerves, and reduced amplitudes of the tail sensory nerves and proprioceptive defects on narrow beam walking test [88]. These animals did not exhibit weakness or abnormalities in thermal sensation, but their large sensory fiber defects persisted for as long as 4 months.

Compared to these earlier reports that used relatively high doses of paclitaxel, lower doses of paclitaxel given intraperitoneally (0.5-2.0 $\mathrm{mg} / \mathrm{kg}$ every other day for a total of 4 doses) to Sprague-Dawley rats resulted in heat-hyperalgesia, mechano-allodynia, mechano-hyperalgesia, and coldallodynia, but had no effect on motor performance [89]. There were no pathological alterations in the sciatic nerve, dorsal root, and dorsal root ganglia at the L4 and L5 levels. The nociceptive effects of paclitaxel resolved within a few weeks. Similarly, another low-dose (0.1-1.0 mg/kg every other day for 2 weeks) intraperitoneal administration protocol in SpragueDawley rats resulted in heat hyperalgesia, mechano-allodynia, and mechano-hyperalgesia that resolved within 2 weeks after cessation of paclitaxel administration [90]. Another low-dose regimen $(2 \mathrm{mg} / \mathrm{kg}$ twice a week for a total of 4 weeks) resulted in reduced sensory nerve conduction velocities and reduced intraepidermal nerve fiber densities in Sprague-Dawley and Wister rats [91]. This was the first study that used intraepidermal nerve fiber density as a measure of distal axonopathy. A similar low-dose regimen $(2 \mathrm{mg} / \mathrm{kg}$ every other day for a total of 4 doses) also showed distal axonal degeneration, as evidenced by reduced intraepidermal nerve fiber densities and mitochondrial abnormalities [92, 93]. Recent studies showed that mitochondria in sensory axons is more susceptible to the toxicity of paclitaxel compared to mitochondria in motor axons, providing a potential hypothesis as to fiber selectivity of paclitaxel-induced neuropathy [94].

In addition to the rat models of paclitaxel CIPN, various mouse models have also been developed [79, 95, 96]. These models predominantly used morphological assessments, including epidermal nerve fiber density [97] as the primary outcome measures. These models have been successfully used to evaluate potential therapeutic compounds [79, 97, 98]. An important concept that emerged from a unique study of paclitaxel CIPN in mice has been the dependency of the phenotype on the genetic background of the mice [99]. This study demonstrated that the various neuropathic pain outcome measures using the same dose of paclitaxel had different effects and did not result in any neuropathic behavior in some of the strains of mice. One potential shortcoming of this otherwise excellent study was the lack of any morphological correlate of the behavior; there was no study of the nerve morphometry or the evaluation of the intraepidermal nerve fibers. Despite this shortcoming, a logical extension of such a comprehensive study would have been to embark on a large-scale genetic study to look for genes that may be "protective" against toxicity of paclitaxel or prevent development of neuropathic pain behavior. The undertaking of such large-scale studies will likely be progressive for the field and may have implications for neuroprotection in other neurodegenerative disorders.

\section{Human Immunodeficiency Virus-Associated Sensory Neuropathy}

Human immunodeficiency virus (HIV) infection and associated treatments can cause many different types of peripheral 
neuropathies, depending on the stage of infection and antiretroviral drugs used (for more detail see Hoke and Cornblath [100]). The most common neurological complication of HIV infection that affects the peripheral nervous system is a sensory predominant distal symmetric polyneuropathy [101]. This distal symmetric polyneuropathy is due to the HIV infection, although the mechanism of neurotoxicity and axonal degeneration is likely to be indirect because there is no direct infection of the sensory neurons [102]. The clinical presentation of HIV-induced distal symmetric polyneuropathy is very similar to a toxic neuropathy associated with antiretroviral therapy. Together, these 2 types of neuropathies are called HIV-associated sensory neuropathies (HIV-SN).

Because there is no direct infection of rodents with HIV, it has been difficult to develop a reliable small animal model of HIV-SN that recapitulates cardinal features of the HIV-SN. Prior in vitro studies indicated that HIV envelope protein gp120 can induce indirect neurotoxicity in rat primary DRG sensory neurons [103] and anti-retroviral drugs, especially nucleoside reverse transcriptase inhibitors, which cause degeneration of established DRG neurites [104] mimicking distal axonopathy seen in HIV-SN patients. Combining these observations, we developed a mouse model of HIV-SN that recapitulates the typical features of early stage HIV-SN [105]. In this transgenic mouse model, gp120 is expressed under the GFAP promoter [106], thereby allowing exposure of only the unmyelinated C-fiber axons to gp120, because in the peripheral nervous system myelinated Schwann cells do not express GFAP, but the unmyelinating Schwann cells do. These mice develop a slow onset distal axonal degeneration of only the small unmyelinated axons by 15 to 18 months of age. However, this process can be accelerated, and neuropathy can be "unmasked" in young animals given daily didanosine [105]. In this mouse model, there is degeneration of distal axons of unmyelinated fibers, as demonstrated by the reduction of a number of unmyelinated axons in the plantar nerves, but not proximally in the sciatic nerves. There is no degeneration of motor or large myelinated axons and behavioral testing correlates with the pathological findings. This mouse model has been useful in evaluating potential therapeutic drugs (Höke et al., unpublished data).

Others have focused on the neuropathic pain that is a cardinal feature of many HIV-SN patients. A single intraperitoneal injection of the anti-retroviral drugs (didanosine or stavudine) caused dose-dependent mechanical hypersensitivity and allodynia in rats [107]. Although this model has been used to evaluate the mechanistic role of caspase signaling and mitochondrial electron transport abnormalities in the neuropathic pain behavior caused by toxic anti-retroviral drugs [108, 109], a major shortcoming of this model has been the lack of evaluation for morphological abnormalities in the distal nerves and transient nature of the neuropathic pain behavior. A slightly different approach by another group was useful in evaluating the efficacy of commonly used medications for neuropathic pain [110]. In this study, the investigators gave intraperitoneal injections of zalcitabine ( 3 times a week for 3 weeks) to Wistar rats, and used both evoked (mechanical hyperalgesia) and nonevoked (anxiety-like behavior in an open field test) pain behavior outcomes. Anxiety-like behavior, presumably due to spontaneous pain, developed in zalcitabine-treated rats and was reduced with gabapentin and morphine. The same group also developed a neuropathic pain model due to the HIV infection per se by intraepineural injection of the HIV envelope protein gp120 into the sciatic nerve [111]. These animals developed transient mechanical hypersensitivity without any alterations in thermal sensation. This model was useful in evaluating the potential therapeutic efficacy of commonly used anti-neuropathic pain medications, such as gabapentin, morphine, and cannabinoids. The neuropathic pain behavior in this model was exacerbated when anti-retroviral drug zalcitabine was given systemically [112], mirroring the experience in the transgenic mouse model of HIV-SN. Furthermore, these animals developed reduction in intraepidermal nerve fiber density, which is consistent with true neuropathy.

Other models of HIV-SN used infection by viruses similar to HIV in susceptible animals. These include neonatal cats infected with the feline immunodeficiency virus [113] and macaques infected with a neurovirulent strain of simian immunodeficiency virus [114]. The macaque model has been useful to demonstrate that the simian immunodeficiency virus-infected animals have defective regenerative capacity of their peripheral nerves [115], and the distal axonal degeneration (as evidenced by reduced intraepidermal nerve fiber densities) seen in these macaques is associated with mitochondrial dysfunction and increased oxidative stress in the distal nerves, but not in the proximal nerves [116]. These latter findings were correlated with increased mutation rate in mitochondrial DNA in distal nerves in HIV-SN patients validating the usefulness of the animal model. The neonatal cat model of HIV-SN also shows reduced intraepidermal nerve fiber density and has been helpful in elucidating potential mechanisms of neurotoxicity of the viral infection $[117,118]$. The cat model has also been used to evaluate the neurotoxicity of anti-retroviral drugs, and the findings confirmed the earlier work demonstrating the mitochondrial dysfunction by anti-retroviral drugs [119]. These large animal models of HIV-SN have been very valuable to evaluate potential mechanisms of neuronal injury, but their usefulness in testing potential therapies in a rapid manner is limited by the high cost associated with these studies.

\section{Conclusions}

In this brief review, we have covered commonly used animal models of 3 types of peripheral neuropathies: 1) diabetic peripheral neuropathy, 2) chemotherapy-induced peripheral 
neuropathy, and 3) HIV-associated sensory neuropathy. A common theme that emerges is that in recent years greater attention has been paid to developing animal models that mimic the human condition more reliably and use outcome measures that are also used in the clinical evaluation of patients of peripheral neuropathies. Most importantly, these outcome measures are the evaluation of distal sensory axons in the skin using a simple immunohistochemical stain. Quantitation of intraepidermal nerve fiber densities, especially when done in a blinded manner, allows 1 to comprehensively evaluate the impact of a given intervention on the disease model. Because the intraepidermal nerve fiber densities can be used in clinical trials as an objective outcome measure, future translational studies may be more predictive of better outcomes in clinical trials.

Acknowledgments This work was supported by the National Institutes of Health (grant NS43991), Dr. Miriam and Sheldon G. Adelson Medical Research Foundation, and the Foundation for Peripheral Neuropathy.

Required Author Forms Disclosure forms provided by the authors are available with the online version of this article.

\section{References}

1. Gregg EW, Sorlie P, Paulose-Ram R, et al. Prevalence of lowerextremity disease in the US adult population $\geq 40$ years of age with and without diabetes: 1999-2000 national health and nutrition examination survey. Diabetes Care 2004;27:1591-1597.

2. Clues to diagnosis of peripheral neuropathy: history and examination of the patient. In: Mendell JR, Kissel J, Cornblath DR, eds. Diagnosis and Management of Peripheral Nerve Disorders. New York: Oxford, 2001:10-29.

3. Chalk C, Benstead TJ, Moore F. Aldose reductase inhibitors for the treatment of diabetic polyneuropathy. Cochrane Database Syst Rev 2007:CD004572.

4. Feldman E. Diabetic neuropathy. Curr Drug Targets 2008;9:1-2.

5. Zochodne D. Diabetes mellitus and the peripheral nervous system: manifestations and mechanisms. Muscle Nerve 2007; 36:144-166.

6. Said G. Diabetic neuropathy - a review. Nat Clin Pract Neurol 2007;3:331-340.

7. Boulton A, Malik R, Arezzo J, Sosenko J. Diabetic somatic neuropathies. Diabetes Care 2004;27:1458-1486.

8. Zochodne D. Diabetic polyneuropathy: an update. Curr Opin Neurol 2008;21:527-533.

9. Yagihashi S, Yamagishi S, Wada R. Pathology and pathogenetic mechanisms of diabetic neuropathy: correlation with clinical signs and symptoms. Diabetes Res Clin Pract 2007;77(suppl 1): S184-S189.

10. Vincent AM, Callaghan BC, Smith AL, Feldman EL. Diabetic neuropathy: cellular mechanisms as therapeutic targets. Nat Rev Neurol 2011;7:573-583.

11. Obrosova IG. Diabetic painful and insensate neuropathy: pathogenesis and potential treatments. Neurotherapeutics: the journal of the American Society for Experimental NeuroTherapeutics 2009;6: 638-647.
12. Llewelyn J, Gilbey S, Thomas P, et al. Sural nerve morphometry in diabetic autonomic and painful sensory neuropathy. A clinicopathological study. Brain 1991;114(pt 2):867-892.

13. Dyck P, Lais A, Karnes J, O'Brien P, Rizza R. Fiber loss is primary and multifocal in sural nerves in diabetic polyneuropathy. Ann Neurol 1986;19:425-439.

14. Said G, Slama G, Selva J. Progressive centripetal degeneration of axons in small fibre diabetic polyneuropathy. Brain 1983;106 (pt 4):791-807.

15. Behse F, Buchthal F, Carlsen F. Nerve biopsy and conduction studies in diabetic neuropathy. J Neurol Neurosurg Psychiatry 1977;40:1072-1082.

16. Sullivan KA, Lentz SI, Roberts JL Jr., Feldman EL. Criteria for creating and assessing mouse models of diabetic neuropathy. Curr Drug Targets 2008;9:3-13.

17. Rakieten N, Rakieten ML, Nadkarni MV. Studies on the diabetogenic action of streptozotocin (NSC-37917). Cancer Chemother Rep 1963;29:91-98.

18. Arison RN, Ciaccio EI, Glitzer MS, Cassaro JA, Pruss MP. Light and electron microscopy of lesions in rats rendered diabetic with streptozotocin. Diabetes 1967;16:51-56.

19. Jakobsen J, Lundbaek K. Neuropathy in experimental diabetes: an animal model. Brit Med J 1976;2:278-279.

20. Schmidt RE, Matschinsky FM, Godfrey DA, Williams AD, McDougal DB Jr. Fast and slow axoplasmic flow in sciatic nerve of diabetic rats. Diabetes 1975;24:1081-1085.

21. Yagihashi S, Kudo K, Nishihira M. Peripheral nerve structures of experimental diabetes rats and the effect of insulin treatment. Tohoku J Exp Med 1979;127:35-44.

22. Brown MJ, Sumner AJ, Greene DA, Diamond SM, Asbury AK. Distal neuropathy in experimental diabetes mellitus. Ann Neurol 1980;8:168-178.

23. Moore SA, Peterson RG, Felten DL, O'Connor BL. A quantitative comparison of motor and sensory conduction velocities in shortand long-term streptozotocin- and alloxan-diabetic rats. J Neurol Sci 1980;48:133-152.

24. Yue DK, Hanwell MA, Satchell PM, Turtle JR. The effect of aldose reductase inhibition on motor nerve conduction velocity in diabetic rats. Diabetes 1982;31:789-794.

25. Chalk C, Benstead TJ, Moore F. Aldose reductase inhibitors for the treatment of diabetic polyneuropathy. Cochrane database of systematic reviews 2007:CD004572.

26. Holland NR, Stocks A, Hauer P, et al. Intraepidermal nerve fiber density in patients with painful sensory neuropathy. Neurology 1997;48:708-711.

27. McCarthy BG, Hsieh ST, Stocks A, et al. Cutaneous innervation in sensory neuropathies: evaluation by skin biopsy. Neurology 1995;45:1848-1855.

28. Shun CT, Chang YC, Wu HP, et al. Skin denervation in type 2 diabetes: correlations with diabetic duration and functional impairments. Brain 2004;127(pt 7):1593-1605.

29. Sumner CJ, Sheth S, Griffin JW, Cornblath DR, Polydefkis M. The spectrum of neuropathy in diabetes and impaired glucose tolerance. Neurology 2003;60:108-111.

30. Lauria G, Lombardi R, Borgna M, et al. Intraepidermal nerve fiber density in rat foot pad: neuropathologic-neurophysiologic correlation. J Periph Nerv Syst 2005;10:202-208.

31. Drel VR, Pacher P, Vareniuk I, et al. A peroxynitrite decomposition catalyst counteracts sensory neuropathy in streptozotocin-diabetic mice. Eur J Pharmacol 2007;569:48-58.

32. Johnson MS, Ryals JM, Wright DE. Early loss of peptidergic intraepidermal nerve fibers in an STZ-induced mouse model of insensate diabetic neuropathy. Pain 2008;140:35-47.

33. Drel VR, Mashtalir N, Ilnytska O, et al. The leptin-deficient (ob/ob) mouse: a new animal model of peripheral neuropathy of type 2 diabetes and obesity. Diabetes 2006;55:3335-3343. 
34. Obrosova IG, Ilnytska O, Lyzogubov VV, et al. High-fat diet induced neuropathy of pre-diabetes and obesity: effects of "healthy" diet and aldose reductase inhibition. Diabetes 2007; 56:2598-2608.

35. Cheng HT, Dauch JR, Hayes JM, Yanik BM, Feldman EL. Nerve growth factor/p38 signaling increases intraepidermal nerve fiber densities in painful neuropathy of type 2 diabetes. Neurobiol Dis 2012;45:280-287

36. Yamakawa I, Kojima H, Terashima T, et al. Inactivation of TNFalpha ameliorates diabetic neuropathy in mice. Am J Physiol Endocrinol Metab 2011;301:E844-E852.

37. Stavniichuk R, Drel VR, Shevalye H, et al. Baicalein alleviates diabetic peripheral neuropathy through inhibition of oxidativenitrosative stress and p38 MAPK activation. Exp Neurol 2011; 230:106-113.

38. Lupachyk S, Shevalye H, Maksimchyk Y, Drel VR, Obrosova IG. PARP inhibition alleviates diabetes-induced systemic oxidative stress and neural tissue 4-hydroxynonenal adduct accumulation: correlation with peripheral nerve function. Free Radic Biol Med 2011;50:1400-1409.

39. Liu WJ, Jin HY, Lee KA, et al. Neuroprotective effect of the glucagon-like peptide-1 receptor agonist, synthetic exendin-4, in streptozotocin-induced diabetic rats. Br J Pharmacol 2011; 164:1410-1420.

40. Dieckmann A, Kriebel M, Andriambeloson E, Ziegler D, Elmlinger $\mathrm{M}$. Treatment with Actovegin(R) improves sensory nerve function and pathology in streptozotocin-diabetic rats via mechanisms involving inhibition of PARP activation. Exp Clin Endocrinol Diabetes 2012;120(03):132-138.

41. Courteix C, Eschalier A, Lavarenne J. Streptozocin-induced diabetic rats: behavioural evidence for a model of chronic pain. Pain 1993;53:81-88.

42. Lee JH, McCarty R. Glycemic control of pain threshold in diabetic and control rats. Physiol Behav 1990;47:225-230.

43. Calcutt NA, Malmberg AB, Yamamoto T, Yaksh TL. Tolrestat treatment prevents modification of the formalin test model of prolonged pain in hyperglycemic rats. Pain 1994;58:413420.

44. Ahlgren SC, Levine JD. Mechanical hyperalgesia in streptozotocindiabetic rats. Neuroscience 1993;52:1049-1055.

45. Malcangio M, Tomlinson DR. A pharmacologic analysis of mechanical hyperalgesia in streptozotocin/diabetic rats. Pain 1998; 76:151-157.

46. Calcutt NA, Jorge MC, Yaksh TL, Chaplan SR. Tactile allodynia and formalin hyperalgesia in streptozotocin-diabetic rats: Effects of insulin, aldose reductase inhibition and lidocaine. Pain 1996; 68:293-299.

47. Malmberg AB, Yaksh TL, Calcutt NA. Anti-nociceptive effects of the GM1 ganglioside derivative AGF 44 on the formalin test in normal and streptozotocin-diabetic rats. Neurosci Lett 1993; 161:45-48.

48. Rossini AA, Williams RM, Mordes JP, Appel MC, Like AA. Spontaneous diabetes in the gnotobiotic BB/W rat. Diabetes 1979;28:1031-1032.

49. Zucker LM, Antoniades HN. Insulin and obesity in the Zucker genetically obese rat "fatty". Endocrinology 1972;90:1320-1330.

50. Brussee V, Guo G, Dong Y, et al. Distal degenerative sensory neuropathy in a long-term type 2 diabetes rat model. Diabetes 2008;57:1664-1673.

51. Kamiya H, Murakawa Y, Zhang W, Sima AAF. Unmyelinated fiber sensory neuropathy differs in type 1 and type 2 diabetes. Diabetes Metab Res Rev 2005;21:448-458.

52. Oltman CL, Davidson EP, Coppey LJ, Kleinschmidt TL, Yorek MA. Treatment of Zucker diabetic fatty rats with AVE7688 improves vascular and neural dysfunction. Diabetes Obes Metab 2009;11:223-233.
53. Stevens MJ, Zhang W, Li F, Sima AAF. C-peptide corrects endoneurial blood flow but not oxidative stress in type $1 \mathrm{BB} /$ Wor rats. Am J Physiol Endocrinol Metab 2004;287:E497-E505.

54. Sullivan KA, Hayes JM, Wiggin TD, et al. Mouse models of diabetic neuropathy. Neurobiol Dis 2007;28:276-285.

55. Courteix C, Bardin M, Chantelauze C, Lavarenne J, Eschalier A. Study of the sensitivity of the diabetes-induced pain model in rats to a range of analgesics. Pain 1994;57:153-160.

56. Yamamoto H, Shimoshige Y, Yamaji T, et al. Pharmacological characterization of standard analgesics on mechanical allodynia in streptozotocin-induced diabetic rats. Neuropharmacology 2009;57:403-408.

57. Kvinesdal B, Molin J, Frøland A, Gram LF. Imipramine treatment of painful diabetic neuropathy. JAMA 1984;251:1727-1730.

58. Max MB, Culnane M, Schafer SC, et al. Amitriptyline relieves diabetic neuropathy pain in patients with normal or depressed mood. Neurology 1987;37:589-596.

59. Max MB, Kishore-Kumar R, Schafer SC, et al. Efficacy of desipramine in painful diabetic neuropathy: a placebo-controlled trial. Pain 1991;45:3-9.

60. Max MB, Lynch SA, Muir J, et al. Effects of desipramine, amitriptyline, and fluoxetine on pain in diabetic neuropathy. NEJM 1992;326:1250-1256.

61. McQuay HJ, Tramèr M, Nye BA, et al. A systematic review of antidepressants in neuropathic pain. Pain 1996;68:217-227.

62. Gimbel JS, Richards P, Portenoy RK. Controlled-release oxycodone for pain in diabetic neuropathy: a randomized controlled trial. Neurology 2003;60:927-934.

63. Watson CPN, Moulin D, Watt-Watson J, Gordon A, Eisenhoffer J. Controlled-release oxycodone relieves neuropathic pain: a randomized controlled trial in painful diabetic neuropathy. Pain 2003;105:71-78.

64. Ziegler D, Dannehl K, Volksw D, et al. Prevalence of cardiovascular autonomic dysfunction assessed by spectral analysis and standard tests of heart-rate variation in newly diagnosed IDDM patients. Diabetes Care 1992;15:908-911.

65. Ziegler D, Gries FA, Spuler M, Lessmann F. The epidemiology of diabetic neuropathy. Diabetic Cardiovascular Autonomic Neuropathy Multicenter Study Group. J Diabetes Complications 1992;6:49-57.

66. Kennedy WR, Navarro X, Sutherland DE. Neuropathy profile of diabetic patients in a pancreas transplantation program. Neurology 1995;45:773-780.

67. Giachetti A. The functional state of sympathetic nerves in spontaneously diabetic mice. Diabetes 1978;27:969-974.

68. Monckton G, Pehowich E. Autonomic neuropathy in the streptozotocin diabetic rat. Can J Neurol Sci 1980;7:135-142.

69. Schmidt RE, Nelson JS, Johnson EM, Jr. Experimental diabetic autonomic neuropathy. Am J Pathol 1981;103:210-225.

70. Schmidt RE, Dorsey DA, Beaudet LN, et al. Experimental rat models of types 1 and 2 diabetes differ in sympathetic neuroaxonal dystrophy. J Neuropathol Exp Neurol 2004;63: 450-460.

71. Wilson HF, Mayer JH, Clarke SA, Tomlinson DR. An examination of autonomic nervous function in genetically diabetic mice. J Auton Pharmacol 1982;2:147-153.

72. Schmidt RE, Scharp DW. Axonal dystrophy in experimental diabetic autonomic neuropathy. Diabetes 1982;31:761-770.

73. Schmidt RE, Beaudet LN, Plurad SB, Dorsey DA. Axonal cytoskeletal pathology in aged and diabetic human sympathetic autonomic ganglia. Brain Res 1997;769:375-383.

74. Schmidt RE, Dorsey DA, Beaudet LN, et al. Insulin-like growth factor I reverses experimental diabetic autonomic neuropathy. Am J Pathol 1999;155:1651-1660.

75. Schmidt RE, Feng D, Wang Q, et al. Effect of insulin and an erythropoietin-derived peptide (ARA290) on established neuritic 
dystrophy and neuronopathy in Akita (Ins2 Akita) diabetic mouse sympathetic ganglia. Exp Neurol 2011;232:126-135.

76. Windebank AJ, Grisold W. Chemotherapy-induced neuropathy. J Peripher Nerv Syst 2008;13:27-46.

77. Argyriou AA, Bruna J, Marmiroli P, Cavaletti G. Chemotherapyinduced peripheral neurotoxicity (CIPN): An update. Crit Rev Oncol Hematol. 2011. doi:10.1016/j.critrevonc.2011.04.012.

78. Roytta M, Raine CS. Taxol-induced neuropathy: chronic effects of local injection. J Neurocytol 1986;15:483-496.

79. Apfel SC, Lipton RB, Arezzo JC, Kessler JA. Nerve growth factor prevents toxic neuropathy in mice. Ann Neurol 1991; 29:87-90.

80. Cavaletti G, Petruccioli MG, Tredici G, et al. Effects of repeated administration of low doses of cisplatin on the rat nervous system. Int J Tissue React 1991;13:151-157.

81. Apfel SC, Arezzo JC, Lipson L, Kessler JA. Nerve growth factor prevents experimental cisplatin neuropathy. Ann Neurol 1992; 31:76-80.

82. Cavaletti G, Tredici G, Braga M, Tazzari S. Experimental peripheral neuropathy induced in adult rats by repeated intraperitoneal administration of taxol. Exp Neurol 1995;133:64-72.

83. Russell JW, Gill JS, Sorenson EJ, Schultz DA, Windebank AJ. Suramin-induced neuropathy in an animal model. J Neurol Sci 2001;192:71-80.

84. Cavaletti G, Gilardini A, Canta A, et al. Bortezomib-induced peripheral neurotoxicity: a neurophysiological and pathological study in the rat. Exp Neurol 2007;204:317-325.

85. Sahenk Z, Brady ST, Mendell JR. Studies on the pathogenesis of vincristine-induced neuropathy. Muscle Nerve 1987;10:80-84

86. Apfel SC, Arezzo JC, Lewis ME, Kessler JA. The use of insulinlike growth factor I in the prevention of vincristine neuropathy in mice. Ann N Y Acad Sci 1993;692:243-245.

87. Roytta M, Raine CS. Taxol-induced neuropathy: further ultrastructural studies of nerve fibre changes in situ. J Neurocytol 1985; 14:157-175.

88. Cliffer KD, Siuciak JA, Carson SR, et al. Physiological characterization of Taxol-induced large-fiber sensory neuropathy in the rat. Ann Neurol 1998;43:46-55.

89. Polomano RC, Mannes AJ, Clark US, Bennett GJ. A painful peripheral neuropathy in the rat produced by the chemotherapeutic drug, paclitaxel. Pain 2001;94:293-304.

90. Dina OA, Chen X, Reichling D, Levine JD. Role of protein kinase Cepsilon and protein kinase A in a model of paclitaxelinduced painful peripheral neuropathy in the rat. Neuroscience 2001;108:507-515.

91. Persohn E, Canta A, Schoepfer S, et al. Morphological and morphometric analysis of paclitaxel and docetaxel-induced peripheral neuropathy in rats. Eur J Cancer 2005;41:1460-1466.

92. Flatters SJ, Bennett GJ. Studies of peripheral sensory nerves in paclitaxel-induced painful peripheral neuropathy: evidence for mitochondrial dysfunction. Pain 2006;122:245-257.

93. Siau C, Xiao W, Bennett GJ. Paclitaxel- and vincristine-evoked painful peripheral neuropathies: loss of epidermal innervation and activation of Langerhans cells. Exp Neurol 2006;201:507-514.

94. Xiao WH, Zheng H, Zheng FY, et al. Mitochondrial abnormality in sensory, but not motor, axons in paclitaxel-evoked painful peripheral neuropathy in the rat. Neuroscience 2011;199:461469.

95. Mimura Y, Kato H, Eguchi K, Ogawa T. Schedule dependency of paclitaxel-induced neuropathy in mice: a morphological study. Neurotoxicology 2000;21:513-520.

96. Wang MS, Davis AA, Culver DG, Glass JD. WldS mice are resistant to paclitaxel (taxol) neuropathy. Ann Neurol 2002;52:442-447.

97. Melli G, Jack C, Lambrinos GL, Ringkamp M, Hoke A. Erythropoietin protects sensory axons against paclitaxel-induced distal degeneration. Neurobiol Dis 2006;24:525-530.
98. Wang MS, Davis AA, Culver DG, et al. Calpain inhibition protects against Taxol-induced sensory neuropathy. Brain 2004; 127(pt 3):671-679.

99. Smith SB, Crager SE, Mogil JS. Paclitaxel-induced neuropathic hypersensitivity in mice: responses in 10 inbred mouse strains. Life Sci 2004;74:2593-2604.

100. Hoke A, Cornblath DR. Peripheral neuropathies in human immunodeficiency virus infection. Suppl Clin Neurophysiol 2004;57:195-210.

101. Cornblath DR, McArthur JC. Predominantly sensory neuropathy in patients with AIDS and AIDS-related complex. Neurology 1988;38:794-796.

102. Pardo C, McArthur J, Griffin J. HIV neuropathy: insights in the pathology of HIV peripheral nerve disease. J Peripher Nerv Syst 2001;6:21-27.

103. Keswani SC, Polley M, Pardo CA, et al. Schwann cell chemokine receptors mediate HIV-1 gp120 toxicity to sensory neurons. Ann Neurol 2003;54:287-296.

104. Keswani SC, Chander B, Hasan C, et al. FK506 is neuroprotective in a model of antiretroviral toxic neuropathy. Ann Neurol 2003;53: 57-64.

105. Keswani SC, Jack C, Zhou C, Hoke A. Establishment of a rodent model of HIV-associated sensory neuropathy. J Neurosci 2006; 26:10299-10304.

106. Toggas SM, Masliah E, Rockenstein EM, et al. Central nervous system damage produced by expression of the HIV-1 coat protein gp120 in transgenic mice. Nature 1994;367:188-193.

107. Joseph EK, Chen X, Khasar SG, Levine JD. Novel mechanism of enhanced nociception in a model of AIDS therapy-induced painful peripheral neuropathy in the rat. Pain 2004;107:147-158.

108. Joseph EK, Levine JD. Caspase signalling in neuropathic and inflammatory pain in the rat. Eur J Neurosci 2004;20:2896-2902.

109. Joseph EK, Levine JD. Mitochondrial electron transport in models of neuropathic and inflammatory pain. Pain 2006;121:105-114

110. Wallace VC, Segerdahl AR, Blackbeard J, Pheby T, Rice AS. Anxiety-like behaviour is attenuated by gabapentin, morphine and diazepam in a rodent model of HIV anti-retroviral-associated neuropathic pain. Neurosci Lett 2008;448:153-156.

111. Wallace VC, Blackbeard J, Pheby T, et al. Pharmacological, behavioural and mechanistic analysis of HIV-1 gp120 induced painful neuropathy. Pain 2007;133:47-63.

112. Wallace VC, Blackbeard J, Segerdahl AR, et al. Characterization of rodent models of HIV-gp120 and anti-retroviral-associated neuropathic pain. Brain 2007;130(pt 10):2688-2702.

113. Kennedy JM, Hoke A, Zhu Y, et al. Peripheral neuropathy in lentivirus infection: evidence of inflammation and axonal injury. Aids 2004:18:1241-1250.

114. Laast VA, Shim B, Johanek LM, et al. Macrophage-mediated dorsal root ganglion damage precedes altered nerve conduction in SIV-infected macaques. Am J Pathol 2011;179:2337-2345.

115. Ebenezer GJ, Laast VA, Dearman B, et al. Altered cutaneous nerve regeneration in a simian immunodeficiency virus / macaque intracutaneous axotomy model. J Comp Neurol 2009;514:272-283.

116. Lehmann HC, Chen W, Borzan J, Mankowski JL, Hoke A. Mitochondrial dysfunction in distal axons contributes to human immunodeficiency virus sensory neuropathy. Ann Neurol 2011;69:100-110.

117. Zhu Y, Jones G, Tsutsui S, et al. Lentivirus infection causes neuroinflammation and neuronal injury in dorsal root ganglia: pathogenic effects of STAT-1 and inducible nitric oxide synthase. J Immunol 2005;175:1118-1126.

118. Zhu Y, Antony J, Liu S, et al. CD8+ lymphocyte-mediated injury of dorsal root ganglion neurons during lentivirus infection: CD154dependent cell contact neurotoxicity. J Neurosci 2006;26:3396-3403.

119. Zhu Y, Antony JM, Martinez JA, et al. Didanosine causes sensory neuropathy in an HIV/AIDS animal model: impaired mitochondrial and neurotrophic factor gene expression. Brain 2007;130(pt 8):20112023. 